\title{
No Role of rs1137101 Variant of the Leptin Receptor Gene in Manifestation of Obesity \\ A Shahid ${ }^{1,2}, \mathrm{~S} \mathrm{Rana}^{1,3}, \mathrm{~S} \mathrm{Mahmood}^{4}$
}

\begin{abstract}
Objective: Obese phenotype can be a consequence of disruption in the physiological integrity of the leptin axis. Leptin acts as a satiety signal and exerts its physiological effect by binding to leptin receptor; consequently, genetic variants of leptin receptor may be important in pathophysiology of human obesity. The current study was, therefore, carried out to find association of leptin receptor rs1137101 variant with obesity and associated anthropometric and metabolic parameters in a sample of Pakistani population.

Methods: DNA samples from a total of 239 obese and 155 non-obese human subjects with age range of 5 to 45 years were genotyped for rs1137101 variant of the leptin receptor gene. Anthropometric measurements of the subjects were taken and biochemical parameters from the corresponding serum samples were determined. Blood pressure (BP) was monitored, and measurements of body weight, height, waist and hip circumference were recorded. Body mass index (BMI) and Waist-to-Hip Ratio (WHR) were calculated. Levels of fasting blood glucose (FBG), insulin, leptin and leptin receptor were determined, and insulin resistance (IR) was calculated.
\end{abstract}

Results: The statistical analysis of the data showed no significant difference in genotype and allele frequencies of rs1137101 variant between obese and non-obese subjects $(\mathrm{P}>0.05)$. Moreover, no significant association of the variant was observed with any of the obesity-related anthropometric and metabolic traits $(\mathrm{P}>0.05)$.

Conclusion: The study suggests that rs1137101 variant of the leptin receptor gene may not be involved in conferring obese phenotype in Pakistani population.

Keywords: Leptin receptor, obesity, Pakistan, rs1137101 variant

From: ${ }^{1}$ Department of Physiology and Cell Biology, University of Health Sciences, Lahore, Pakistan. ${ }^{2}$ Department of Physiology, Shalamar Medical and Dental College, Lahore, Pakistan. ${ }^{3}$ International Center for Chemical and Biological Sciences (ICCBS), University of Karachi, Karachi, Pakistan. ${ }^{4}$ Department of Human Genetics and Molecular Biology, University of Health Sciences, Lahore, Pakistan.

Correspondence: Dr S Mahmood, Department of Human Genetics and Molecular Biology. University of Health Sciences, Lahore, Pakistan. Fax: +92-42-99230394, e-mail: sqb_medgen@yahoo.com, medgen@uhs.edu.pk 


\section{INTRODUCTION}

Leptin receptor (LEPR) is a single transmembrane protein that belongs to class I cytokine receptor family (1). Leptin, an adipokine and central regulator for adiposity-sensing pathways, exerts its physiological effect by binding to LEPR in the hypothalamus. It functions as a satiety signal by downregulating orexigenic (appetite-stimulating) peptides and upregulating anorexigenic (appetite-decreasing) peptides (2). LEPR is a product of the leptin receptor gene that is located on human chromosome $1 \mathrm{p} 31$ and consists of 20 exons (3). The expression of the leptin receptor gene results in at least six isoforms of leptin receptors (LEPRa-f) attributable to alternative mRNA splicing. The isoforms ( $\mathrm{Ra}, \mathrm{Rb}, \mathrm{Rc}, \mathrm{Rd}$ and $\mathrm{Rf}$ ) share the same extracellular and transmembrane domains but differ in the length of the intracellular domain (4).

The secreted isoform Re lacking both transmembrane and intracellular domains can be generated either by alternative splicing $(\mathrm{Ob}-\mathrm{Re})$ or by ectodomain shedding. It circulates as a soluble receptor, and may be involved in modulating leptin activity $(5,6)$. Leptin receptors form homodimers, and binding of the leptin to the receptors activates Janus activated Kinases (JAK), which in turn activate signal transducers and activators of transcription (STAT). Leptin signaling through the JAKs and activation of transcription system for regulating body fat mass is mainly associated with the longest form (LEPRb) of leptin receptor that contains both conserved sequence motifs necessary for the binding of the Janus activated kinases (JAK) and STAT family of signal transducing factors required for full leptin signaling function (7). The shorter isoforms lack STAT binding element, thus having reduced signal transduction capabilities (8). The longest isoform appears to be the most abundant in the hypothalamus, while the shorter isoforms seem to predominate in peripheral tissues (9). 
LEPR gene has been extensively studied in search for several common variants that may be important in pathophysiology of human obesity (10). One of these variants is nonsynonymous Q223R (rs1137101) in exon 6 of the human LEPR gene at codon 223 (11). LEPR contains two extracellular cytokine receptor homology domains (CRH1 and CRH2). CRH2 domain is necessary and sufficient for leptin binding whereas CRH1 is not essential for a high affinity interaction (12). Q223R variant results from an A to $G$ transversion at nucleotide 668 from the start codon encoding a glutamine $(\mathrm{Q})$ to arginine (R) substitution in the N-terminal CRH1 domain of LEPR (13). Genetic variants, which serve as causal factors for a particular population may or may not affect the other population. In particular, the data on the status of this variant in relation to obesity in Pakistani population has remained extremely scarce. The current study was, therefore, undertaken to find the association of Q223R variant of the LEPR gene with obesity and obesity-related anthropometric and metabolic traits in a sample of Pakistani population.

\section{SUBJECTS AND METHODS}

The study was performed at University of Health Sciences Lahore after the approval from the Institutional Review Board of the University. All procedures involving collection of blood samples, and anthropometric measurements were carried out with the adequate understanding and written informed consent of the subjects.

\section{Study population}

The participants of the study involved 239 obese individuals with BMI $\geq 30 \mathrm{Kg} / \mathrm{m}^{2}$ or $\geq 95$ th percentile and 155 control subjects with $\mathrm{BMI}<25 \mathrm{Kg} / \mathrm{m}^{2}$ or 5 th- 85 th percentile. The age range 
of the participants was between 5 to 45 years. Simple random sampling was applied for the collection of blood specimens. Subjects with the history of any endocrine disorder were not included in the study. Similarly, subjects who were taking antidepressants, anticonvulsants and steroids were not included in the study.

\section{Categorization of study population}

Subjects were further classified into two categories: Category 1 involving individuals $\leq 18$ years of age and category 2 involving individuals $>18$ years of age. The subjects $>18$ years of age were considered obese by $\mathrm{BMI} \geq 30$ and normal weight $\mathrm{BMI}<25$ (14). The subjects $\leq 18$ years of age were considered obese by $\geq 95$ th percentile and normal weight by 5 th -85 th percentile by following BMI for age growth charts recommended by Center for Disease Control and Prevention (CDC).

\section{Demographic information and physical examination}

Full demographic information including name, age, sex, address, education and socioeconomic status was documented on a questionnaire. Complete general physical examination was carried out. A blood volume of $5 \mathrm{ml}$ was collected from each subject aseptically.

\section{Anthropometric and Blood Pressure Measurements}

Body weight, height, waist (WC) and hip circumference (HC), systolic blood pressure (SBP) and diastolic blood pressure (DBP) were measured by standard procedures (14). Body height was taken by stadiometer and body weight was measured on digital weighing scale. The body mass index (BMI) of each subject was calculated as weight in kilograms divided by height in meters 
squared. WC was taken just above the belly button in the middle of the lower border of the costal margin and uppermost border of the iliac crest to the nearest $0.1 \mathrm{~cm}$. Hip circumference was measured as the maximal circumference over the buttocks. Waist-to-hip ratio was calculated from the values of waist and hip circumference. BP was taken two times in a sitting position from the right arm of the subject by a standard mercury sphygmomanometer.

\section{Biochemical measurements}

Blood samples were collected after an overnight fast of 8-12 hours. Fasting blood glucose (FBG) levels were determined by the glucose oxidase method on Huma Star 180 chemistry analyzer (Human, Wiesbaden, Germany). Blood insulin, leptin and leptin receptor levels were determined by ELISA (enzyme-linked immunosorbent assay) using commercial kit on an automated EIA analyzer (Bio-Rad Laboratories, Hercules, CA, USA). FBG and fasting insulin concentrations were taken to measure homeostasis model assessment of insulin resistance (HOMA-IR). HOMA$\mathrm{IR}=$ Fasting insulin $(\mu \mathrm{IU} / \mathrm{ml}) \times$ Fasting glucose $(\mathrm{mmol} / \mathrm{l}) / 22.5(15)$.

\section{DNA Extraction and Genotyping of rs1137101 Variant}

DNA was extracted from whole blood using genomic DNA purification kit (Fermentas, USA). Genotyping of rs1137101 variant was carried out by PCR-RFLP (polymerase chain reactionrestriction fragment length polymorphism assay). A DNA fragment containing rs1137101 variant site was amplified using a specific forward (5'TAAGCTGGGTGTCCCAAATA3') and reverse (5'AGCAAAGTGAGATAAGCT3') primer-pair. The PCR was done on Icycler 5 (BioRad, USA). PCR reaction mix was composed of $100 \mu \mathrm{g}$ DNA, $1 \mathrm{X}$ Taq buffer, $2 \mathrm{mM} \mathrm{MgCl} 2,0.2 \mathrm{mM}$ of each dNTP, $10 \rho \mathrm{pmol}$ of each primer and $0.5 \mathrm{U}$ Taq DNA polymerase in a final volume of 25 
$\mu 1$. PCR conditions involve: initial denaturation at $95^{\circ} \mathrm{C}$ for $4 \mathrm{~min}$, followed by 35 cycles of denaturation at $94^{\circ} \mathrm{C}$ for $30 \mathrm{sec}$, annealing at $58^{\circ} \mathrm{C}$ for $30 \mathrm{sec}$ and extension at $72^{\circ} \mathrm{C}$ for $1 \mathrm{~min}$, and then a final extension step at $72^{\circ} \mathrm{C}$ for $10 \mathrm{~min}$. MspI restriction enzyme (Favorgen, Taiwan) was used to digest amplified products of $424 \mathrm{bp}$ in order to examine rs1137101 variant by RFLP assay. Presence of A allele generated a single fragment of $424 \mathrm{bp}$ whereas presence of G allele revealed two fragments of $285 \mathrm{bp}$ and $139 \mathrm{bp}$ (Fig.1)

\section{Statistical Analysis}

The Statistical Package for Social Sciences (SPSS Inc. Chicago, IL, USA, version 17.0) software was used for analyzing the data. Quantitative variables were expressed as mean \pm standard error of mean (SEM). Student's t-test was applied to observe the differences between cases and controls. The whole data was stratified according to age and sex in sub-categories.

Hardy Weinberg equilibrium test (HWE) was applied to determine the variation in distribution of alleles and genotypes. Allelic frequencies were calculated by gene counting. Chi-square $\left(\chi^{2}\right)$ test was used to determine the significant differences of genotype and allelic frequencies between study and control groups. Association of rs1137101 variant (A>G transition) with obesity was determined by Pearson Chi-square using co-dominant, dominant and recessive models. Odds ratio (OR) and 95\% confidence interval (CI) were calculated to determine the risk of obesity associated with the risk allele. The association of rs1137101 variant with anthropometric and metabolic traits was determined using General Linear Model (GLM) assuming co-dominant, dominant and recessive genetic models. The genotypes were coded as $(0,1$ and 2$)$ in codominant model, $(0$ and 1$)$ in dominant model and $(1,0)$ in recessive model corresponding to the number of copies of risk allele. Analysis of Variance (ANOVA), Tukey post hoc analysis and t- 
test were applied to test the differences of obesity-related anthropometric and metabolic traits across genotypes of rs1137101 variant adjusted for age and sex. Bonferroni adjustment was carried out for multiple comparisons. A $P$-value of $<0.05$ was considered statistically significant.

\section{RESULTS}

Obese subjects and high risk factors for

Cardiometabolic Disorders In our study, family history of obesity (FHO) was found in 77\% of the obese subjects (one or both parents) as compared to FHO in $31 \%$ of the control subjects. Hypertension was found in $18 \%$ of the obese subjects whereas no control subject was found to be hypertensive. Similarly, among obese subjects, 7\% were found to have Type 2 diabetes (T2D) and $33.4 \%$ had impaired fasting glucose (IFG) in comparison to $2 \%$ of the control subjects were diabetic and 3\% had IFG. Acanthosis nigricans (AN) was observed in $43 \%$ of the obese subjects as compared to $3.2 \%$ of the controls. Cardiovascular disease (CVD) was observed in $4.2 \%$ of the obese subjects whereas no control subject had CVD. There was no significant difference found between body heights (HT) of obese and control subjects. Waist, hip circumference and WHR of obese subjects were found significantly greater than that of control subjects $(p<0.05)$. Obese subjects were found to have significantly higher SBP and DBP $(\mathrm{p}<0.05)$ as compared to the control subjects. Insulin levels and HOMA-IR values of obese subjects were found significantly $(p<0.05)$ higher as compared to that of control subjects. Leptin levels of the obese subjects were higher and leptin receptor levels were significantly lower as compared to that of control subjects. This above comparison of various parameters between obese and control subjects clearly indicate that obese individuals are more prone to develop various cardiometabolic disorders. 


\section{Genotypic frequencies of rs1137101 variant in obese and control subjects}

The genotypes of rs1137101 variant were in Hardy-Weinberg equilibrium $(p>0.05)$ in both obese and control individuals. There was no significant difference $(p>0.05)$ in the genotype and allele frequencies of LEPR rs1137101 variant between obese and control subjects (Table 1). Analysis of whole data after stratification by gender revealed no significant difference in the genotype and allele frequencies $(\mathrm{p}>0.05)$ between obese and non-obese males and similarly obese and non-obese females (Table 1). When all obese and control subjects were further stratified according to age in two categories $\leq 18$ years and $>18$ years, no significant difference was found in the genotype and allele frequencies between obese and control subjects $>18$ years and $\leq 18$ years $(\mathrm{p}>0.05)$ (Table 1$)$. Similarly, stratification of obese and control subjects $>18$ years and $\leq 18$ years into male and female sub-categories revealed no significant difference in genotype and allele frequencies between $>18$ years obese and control females, $>18$ years obese and control males, $\leq 18$ years obese and control females, and $\leq 18$ years obese and control males

(Table 1). Overall, these results revealed no significant difference in the frequencies of genotypes and alleles between obese and control subjects with and without stratification of the data according to age and gender.

\section{Lepr rs1137101 variant and obesity}

No significant association of any genotype or allele of LEPR rs1137101 was observed with obesity $(\mathrm{p}>0.05)$ in any of the genetic models (co-dominant, dominant and recessive models) used in the current study (Table 1). When the whole data was stratified according to age and sex, again no significant association of any LEPR rs1137101 genotype or allele with obesity was 
found in any of the sub-categories $(p>0.05)$. Thus, no age and gender specific association of LEPR rs1137101 variant with obesity was observed in our study (Table1).

\section{Lepr rs1137101 variant and various obesity grades}

The whole study population was stratified with respect to WHO criteria of BMI in to overweight (BMI 25.00-29.99), obese grade I (BMI 30.00-34.99), obese grade II (BMI 35.00-39.99), obese grade III (BMI $\geq 40.00)$, and also super obese $(\geq 50)$ groups. No significant association $(\mathrm{p}>0.05)$ of any genotype (AA, AG or GG) with any grade of obesity was observed (Table 2).

LEPR rs1137101 Variant and, Anthropometric and Metabolic Traits

GLM multivariate analysis revealed no significant association $(\mathrm{p}>0.05)$ of LEPR rs1137101 variant with any of the anthropometric and metabolic traits including BW, HT, BMI, WC, HC, WHR, SBP, DBP, FBG, insulin levels, HOMA-IR, and leptin and leptin receptor levels (Table 3). There were no significant differences $(p>0.05)$ in anthropometric and metabolic parameters observed between carriers of AA, AG and GG genotypes (Table 3).

\section{DISCUSSION}

The current study examined the association of leptin receptor rs 1137101 variant with obesity and associated anthropometric and metabolic parameters in obese and non-obese subjects of Pakistani population. Both obese male and female subjects of the current study showed higher WHR than normal values but male subjects with obesity had significantly higher WHR than female subjects with obesity and therefore, they were predisposed to high risk of developing 
CVD (16). WHR $>0.9$ in males and $>0.85$ in females is considered as a parameter for the diagnosis of CVD (17).

In the current study, obese subjects had significantly higher leptin levels as compared to control subjects; hyperleptinemia and leptin resistance might be involved in the development of hyperinsulinemia and insulin resistance as shown by high HOMA-IR in the obese subjects of our study, a risk for development of T2D in later life (18). High FBG and high insulin levels found in obese subjects of our study might serve as a biomarker of disturbed carbohydrate metabolism and a future risk for T2D in these subjects. A significant correlation of plasma leptin levels with BMI in obese subjects was also seen in the current study. This observation is in agreement with the previous reports $(19,20)$. Moreover, a positive correlation of leptin with BMI, waist and hip circumference, IR and SBP in the obese subjects of the current study suggests that it is a possible risk factor for predisposition to hypertension (HTN), CVD and T2D. A high leptin level induces endothelial damage and inflammatory reaction in blood vessels; these alterations may contribute to the pathogenesis of HTN (21).

Lack of association between rs1137101 variant the of LEPR gene and obesity in our study indicates that amino acid change as a result of this polymorphism might not affect the phenotype of the subject in our population. This variant occurs in the CRH1 domain, which is not essential for high affinity leptin binding (12). Stratigopoulos et al. (2009) observed no difference in adiposity between wild-type and Q223R isogenic mice fed a high fat diet. Recently, Verkerke et al. (2014) also reported that the rs1137101 variant in the LEPR extracellular CRH1 domain does not affect the rates at which leptin binds to and dissociates from its receptor (22).

Regarding the role of rs1137101 variant in obesity, the results of different association studies are controversial. The present study showed no association of this variant with obesity in 
adults or in younger group ( $\leq 18$ years). Likewise, no significant difference was observed in anthropometric parameters such as BMI, waist and hip circumference and WHR across genotypes of this variant. These findings are consistent with initial studies that also failed to identify any association of this variant with the risk of obesity (23-27). Later on the pooled- and meta-analysis of genetic data by Heo et al $(10,28)$ revealed conflicting results regarding the association of this polymorphism with BMI. Another meta-analysis by Paracchini et al. (29) involving ten studies carried out in Asians, Caucasians, Pima Indians and Brazilians also reported no association of this variant with obesity. Large variation in the allelic frequency across different ethnicities and countries has been reported. Asian population (Japan and Korea) showed relatively higher frequency $(0.85)$ of $\mathrm{G}$ allele than other populations. In contrast, our study reported low (0.35) allelic frequency of G allele. Yiannakouris et al. (30) observed increase risk of obesity in $\mathrm{G}$ allele carriers whereas Portolés et al. (31) found inverse association of rs1137101 variant with obesity, which described that carriers of $\mathrm{G}$ allele had low BMI in Mediterranean Spanish population; later on similar results were reported by Furusawa et al. (32) in Pacific Island population demonstrating that carriers of A allele had high BW and BMI. Lack of association of rs1137101 genetic variant with obesity in the present study is in agreement with a recent study on Turkish children (33).

The present study also reported no difference in the metabolic parameters such as FBG, insulin, HOMA-IR, leptin and leptin receptor levels across genotypes of rs1137101 variant. Lack of association of rs1137101 variant with leptin levels in the current study is in line with the previous report (29). Guízar-Mendoza et al. (34) reported high body fat percentage and plasma leptin levels in carriers of A allele and low in G allele carriers of Mexican adolescent population. However, another study reported high plasma leptin levels in G allele carriers in Greek subjects 
(30). There was no association of plasma leptin receptor levels with rs1137101 variant in our study that is similar to the observation of Ogawa et al. in Japanese population (35).

The current study showed no association of rs1137101 variant with obesity in both males and females whereas Masuo et al. reported gender specific effect with association of this variant with obesity in Caucasian males (36). Another study in Caucasians reported association of higher BMI with $G$ allele carrier girls but not in boys (37). A recent meta-analysis revealed no association of rs1137101 variant with overweight and obesity including no gender specific effect and hence supports the results of the current study (38). The lack of association of rs1137101 variant with obesity and obesity related anthropometric and biochemical parameters seen in the current study is also in agreement with many previous reports $(23-27,29,33,37-38)$. However, a recent study from Pakistan reported the association of rs1137101 variant with body mass index, systolic and diastolic blood pressure, and weight in obese subjects (39). This disagreement with our study may be attributable to the differences in the inclusion and exclusion criteria of the two studies.

In a nutshell, lack of association of rs1137101 variant of the LEPR gene with obesity and obesity related anthropometric and metabolic traits in our study implies that this variant appears to have no role in causing susceptibility of our population to obesity and associated cardiometabolic disorders. The findings of the current study can be further validated by conducting more similar studies with same exclusion and inclusion criteria and by considering a bigger sample size. 


\section{ACKNOWLEDGMENTS}

The authors are grateful to the Higher Education Commission (HEC) of Pakistan for provision of research grant for this study under the project entitled as "Centre for Research in Endocrinology and Reproductive Sciences" (CRERS).

\section{AUTHORS' NOTE}

Authors declare that they have no conflict of interest. 


\section{REFERENCES}

1. Tartaglia LA, Dembski M, Weng X, Deng N, Culpepper J, Devos R, et al. Identification and expression cloning of a leptin receptor, OB-R. Cell 1995; 83: 1263-71.

2. Jéquier E. Leptin signaling, adiposity, and energy balance. Ann N Y Acad Sci 2002; 967: $379-88$.

3. Winick JD, Stoffel M, Friedman JM. Identification of microsatellitemarkers linked to the human leptin receptor gene on chromosome 1. Genomics 1996; 36: 221-2.

4. Lee GH, Proenca R, Montez JM, Carroll KM, Darvishzadeh JG, Lee JI, et al. Abnormal splicing of the leptin receptor in diabetic mice. Nature 1996; 379: 632-5.

5. Huang L, Wang Z, Li C. Modulation of circulating leptin levels by its soluble receptor. J Biol Chem 2001; 276: 6343-9.

6. Ge HF, Huang L, Pourbahram T, Li C. Generation of soluble leptin receptor by ectodomain shedding of membrane-spanning receptors in vitro and in vivo. J Biol Chem 2002; 277: 45898-903.

7. Baumann H, Morella KK, White DW, Dembski M, Bailon PS, et al. The full-length leptin receptor has signaling capabilities of interleukin 6-type cytokine receptors. Proc Natl Acad Sci USA 1996; 93: 8374-8.

8. Bjørbaek C, Uotani S, da Silva B, Flier JS. Divergent signaling capabilities of the long and short isoforms of the leptin receptor. J Biol Chem 1997; 272:32686-95.

9. Zabeau L, Lavens D, Peelman F, Eyckerman S, Vandekerckhove J, Tavernier J. The ins and outs of leptin receptor activation. FEBS Lett 2003; 546: 45-50. 
10. Heo M, Leibel RL, Boyer BB, Chung WK, Koulu M, Karvonen MK et al. Pooling analysis of genetic data: the association of leptin receptor (LEPR) polymorphisms with variables related to human adiposity. Genetics 2001; 159: 1163-78.

11. Thompson DB, Ravussin E, Bennett PH, Bogardus C. Structure and sequence variation at the human leptin receptor gene in lean and obese Pima Indians. Hum Mol Genet 1997; 6: 675-9.

12. Peelman F, Beneden KV, Zabeau L, Iserentant H, Ulrichts P, Defeau D et al. Mapping of the Leptin Binding Sites and Design of a Leptin Antagonist. J Biol Chem 2004; 279: $41038-46$.

13. Stratigopoulos G, LeDuc CA, Matsuoka N, Gutman R, Rausch R, Robertson SA, et al. Functional consequences of the human leptin receptor (LEPR) Q223R transversion. Obesity (Silver Spring) 2009; 17: 126-35.

14. World Health Organization. Measuring Obesity-Classification and Description of Anthropometric Data. in: Report on a WHO Consultation on the Epidemiology of Obesity. ed 2. WHO, Warsaw, Poland; 1987: 2-7.

15. Matthews DR, Hosker JP, Rudenski AS, Naylor BA, Treacher DF, Turner RC. Homeostasis model assessment: insulin resistance and $\beta$-cell function from fasting plasma glucose and insulin concentrations in man. Diabetologia 1985; 28: 412-9.

16. Sundell J, Raitakari OT, Viikari J, Kantola I, Nuutila P, Knuuti J. Both BMI and waist circumference are associated with coronary vasoreactivity in overweight and obese men. Obes Facts 2012; 5: 693-9.

17. Dalton M, Cameron AJ, Zimmet PZ, Shaw JE, Jolley D, Dunstan DW, et al. AusDiab Steering Committee. Waist circumference, waist-hip ratio and body mass index and their 
correlation with cardiovascular disease risk factors in Australian adults. J Intern Med 2003; 254: 555-63.

18. Covey SD, Wideman RD, McDonald C, Unniappan S, Huynh F, Asadi A et al. The pancreatic beta cell is a key site for mediating the effects of leptin on glucose homeostasis. Cell Metab 2006; 4: 291-302.

19. Kostalova L, Leskova L, Kapellerova A, Strbak V. Body mass, plasma leptin, glucose insulin and C-peptide in offspring of diabetic and non-diabetic mothers. Eur J Endocrinol 2001; 145: 53-8.

20. Shahid A, Lone KP, Saeed S, Arslan M. Male offspring of both diabetic parents have higher Insulin resistance and serum leptin levels compared to those with one diabetic parent. Hormones 2008; 7: 313-9.

21. Correia ML, Haynes WG. Leptin, obesity and cardiovascular disease. Curr Opin Nephrol Hypertens. 2004; 13: 215-23.

22. Verkerke H, Naylor C, Zabeau L, Tavernier J, Petri WA Jr, Marie C. Kinetics of leptin binding to the Q223R leptin receptor. PLoS One 2014; 9: e94843.

23. Considine RV, Considine EL, Williams CJ, Hyde TM, Caro JF. The hypothalamic leptin receptor in humans: identification of incidental sequence polymorphisms and absence of the $\mathrm{db} / \mathrm{db}$ mouse and fa/fa rat mutations. Diabetes. 1996; 45: 992-4.

24. Echwald SM, Sørensen TD, Sørensen TI, Tybjaerg-Hansen A, Andersen T, Chung WK, et al. Amino acid variants in the human leptin receptor: lack of association to juvenile onset obesity. Biochem Biophys Res Commun 1997; 233: 248-52. 
25. Gotoda T, Manning BS, Goldstone AP, Imrie H, Evans AL, Strosberg AD, et al. Leptin receptor gene variation and obesity: lack of association in a white British male population. Hum Mol Genet 1997; 6: 869-76.

26. Silver K, Walston J, Chung WK, Yao F, Parikh VV, Andersen R, et al. The Gln223Arg and Lys656Asn polymorphisms in the human leptin receptor do not associate with traits related to obesity. Diabetes 1997; 46: 1898-900.

27. Matsuoka N, Ogawa Y, Hosoda K, Matsuda J, Masuzaki H, Miyawaki T, et al. Human leptin receptor gene in obese Japanese subjects: evidence against either obesity-causing mutations or association of sequence variants with obesity. Diabetologia 1997; 40: 1204 10.

28. Heo M, Leibel RL, Fontaine KR, Boyer BB, Chung WK, Koulu M, et al. A meta-analytic investigation of linkage and association of common leptin receptor (LEPR) polymorphisms with body mass index and waist circumference. Int J Obes Relat Metab Disord 2002; 26: 640-6.

29. Paracchini V, Pedotti P, Taioli E. Genetics of leptin and obesity: a HuGE review. Am J Epidemiol 2005; 162: 101-14.

30. Yiannakouris N, Yannakoulia M, Melistas L, Chan JL, Klimis-Zacas D, Mantzoros CS. The Q223R polymorphism of the leptin receptor gene is significantly associated with obesity and predicts a small percentage of body weight and body composition variability. J Clin Endocrinol Metabol. 2001; 86: 4434-9.

31. Portolés O, Sorlí JV, Francés F, Coltell O, González JI, Sáiz C, et al. Effect of genetic variation in the leptin gene promoter and the leptin receptor gene on obesity risk in a population-based case-control study in Spain. Eur J Epidemiol. 2006; 21: 605-12. 
32. Furusawa T1, Naka I, Yamauchi T, Natsuhara K, Kimura R, Nakazawa M, et al. The Q223R polymorphism in LEPR is associated with obesity in Pacific Islanders. Hum Genet 2010; 127: 287-94.

33. Komşu-Ornek Z, Demirel F, Dursun A, Ermiş B, Pişkin E, Bideci A. Leptin receptor gene Gln223Arg polymorphism is not associated with obesity and metabolic syndrome in Turkish children. Turk J Pediatr 2012; 54: 20-4.

34. Guízar-Mendoza JM, Amador-Licona N, Flores-Martínez SE, López-Cardona MG, Ahuatzin-Trémary R, Sánchez-Corona J. Association analysis of the Gln223Arg polymorphism in the human leptin receptor gene, and traits related to obesity in Mexican adolescents. J Hum Hypertens 2005; 19: 341-6.

35. Ogawa T, Hirose H, Yamamoto Y, Nishikai K, Miyashita K, Nakamura H, et al. Relationships between serum soluble leptin receptor level and serum leptin and adiponectin levels, insulin resistance index, lipid profile, and leptin receptor gene polymorphisms in the Japanese population. Metabolism 2004; 53: 879-85.

36. Masuo K, Straznicky NE, Lambert GW, Katsuya T, Sugimoto K, Rakugi H, et al. Leptinreceptor polymorphisms relate to obesity through blunted leptin mediated sympathetic nerve activation in a Caucasian male population. Hypertens Res 2008; 31:1093-100.

37. Riestra P, Garcia-Anguita A, Schoppen S, Lopez-Simon L, De Oya M, Garcés C. Sexspecific association between leptin receptor polymorphisms and leptin levels and BMI in healthy adolescents. Acta Paediatr 2010; 99: 1527-30.

38. Bender N, Allemann N, Marek, D, Vollenweider P, Waeber G, Mooser V et al. Association between Variants of the Leptin Receptor Gene (LEPR) and Overweight: A Systematic Review and an Analysis of the CoLaus Study. PLoS One 2011; 6: e26157. 
39. Shabana NA, Hasnain S. Association of the leptin receptor Gln223 Arg polymorphism with lipid profile in obese Pakistani subjects. Nutrition 2015; 31:1136. 
Table 1: Genotype and allele distribution of LEPR rs1137101 variant in obese and non-obese subjects

\begin{tabular}{|c|c|c|c|c|c|c|c|c|c|c|c|c|c|c|c|c|c|c|c|c|c|c|c|c|c|c|c|}
\hline & \multicolumn{2}{|c|}{$\begin{array}{c}\text { All } \\
\text { Subjects }\end{array}$} & & \multicolumn{3}{|c|}{ Females } & \multicolumn{3}{|c|}{ Males } & \multicolumn{3}{|c|}{$>18 \mathrm{yrs}$} & \multicolumn{3}{|c|}{$\begin{array}{c}\text { Females } \\
>18 \text { yrs }\end{array}$} & \multicolumn{3}{|c|}{$\begin{array}{c}\text { Males } \\
>18 \text { yrs }\end{array}$} & \multicolumn{2}{|c|}{$\leq 18 \mathrm{yrs}$} & & \multicolumn{2}{|c|}{$\begin{array}{c}\text { Females } \\
\leq 18 \text { yrs }\end{array}$} & \multicolumn{4}{|c|}{$\begin{array}{l}\text { Males } \\
\leq 18 \text { yrs }\end{array}$} \\
\hline & & Non- & & & Non- & & & Non- & & & Non- & & & Non- & & & Non- & & & Non- & & & Non- & & & Non- & \\
\hline & Obese & Obese & & Obese & Obese & & Obese & Obese & & Obese & Obese & & Obese & Obese & & Obese & Obese & & Obese & Obese & & Obese & Obese & & Obese & Obese & \\
\hline & & & $\mathbf{x} 2 /$ & & & $\mathbf{x} 2 /$ & & & $\mathbf{x} 2 /$ & & & $\mathbf{x} 2 /$ & & & $\mathbf{x} 2 /$ & & & $\mathbf{x} 2 /$ & & & $\mathbf{x}^{2}$ & & & $\mathbf{x}^{2} /$ & & & $\mathbf{x}^{2} /$ \\
\hline & & & $\mathbf{P} /$ & & & $\mathbf{P} /$ & & & $\mathbf{p} /$ & & & $\mathbf{P} /$ & & & $\mathbf{P} /$ & & & P/ & & & $\mathbf{P} /$ & & & $\mathbf{P} /$ & & & P/ \\
\hline & $\mathrm{n}=237$ & $\mathrm{n}=131$ & OR & $\mathrm{n}=127$ & $\mathrm{n}=74$ & OR & $\mathrm{n}=110$ & $\mathrm{n}=57$ & OR & $\mathrm{n}=160$ & $\mathrm{n}=87$ & OR & $\mathrm{n}=96$ & $n=41$ & OR & $\mathrm{n}=64$ & $\mathrm{n}=46$ & OR & $\mathrm{n}=77$ & $\mathrm{n}=44$ & OR & $\mathrm{n}=31$ & $\mathrm{n}=33$ & OR & $\mathrm{n}=46$ & $\mathrm{n}=11$ & OR \\
\hline \multicolumn{28}{|l|}{ Co- } \\
\hline \multicolumn{28}{|l|}{ dominant } \\
\hline & 34 & 18 & & 18 & 13 & & 16 & 6 & & 27 & 12 & & 16 & 6 & & 11 & 6 & & 7 & 7 & & 2 & 7 & & 5 & & \\
\hline GG & $(14 \%)$ & $(14 \%)$ & & $(14 \%)$ & $(17 \%)$ & & $(14.5 \%)$ & $(11 \%)$ & & $(17 \%)$ & $(14 \%)$ & & $(17 \%)$ & $(15 \%)$ & & $(17 \%)$ & $(13 \%)$ & & $(9 \%)$ & $(16 \%)$ & & $(6 \%)$ & $(21 \%)$ & & $(11 \%)$ & 0 & \\
\hline & 98 & 56 & $0.073 /$ & 56 & 30 & $0.48 /$ & 42 & 28 & $1.93 /$ & 70 & 39 & $0.41 /$ & 43 & 17 & $0.35 /$ & 27 & 22 & 0.50 & 28 & 19 & $2.51 /$ & 13 & 13 & 3.021 & 15 & 6 & $2.55 /$ \\
\hline $\mathrm{AG}$ & $(41 \%)$ & $(43 \%)$ & 0.964 & $(44 \%)$ & $(41 \%)$ & 0.78 & $(38 \%)$ & $(49 \%)$ & 0.38 & $(44 \%)$ & $(45 \%)$ & 0.81 & $(44 \%)$ & $(41 \%)$ & 0.83 & $(42 \%)$ & $(48 \%)$ & 0.77 & $(36 \%)$ & $(43 \%)$ & 0.28 & $(42 \%)$ & $(39 \%)$ & 0.21 & $(33 \%)$ & $(55 \%)$ & 0.27 \\
\hline & 105 & 57 & & 53 & 31 & & 52 & 23 & & 63 & 36 & & 37 & 18 & & 26 & 18 & & 42 & 18 & & 16 & 13 & & 26 & 5 & \\
\hline $\mathrm{AA}$ & $(44 \%)$ & $(43 \%)$ & & $(41 \%)$ & $(42 \%)$ & & $(47 \%)$ & $(40 \%)$ & & $(39 \%)$ & $(41 \%)$ & & $(39 \%)$ & $(44 \%)$ & & $(40 \%)$ & $(39 \%)$ & & $(55 \%)$ & $(41 \%)$ & & $(52 \%)$ & $(39 \%)$ & & $(56 \%)$ & $(45 \%)$ & \\
\hline \multicolumn{28}{|l|}{ Dominant } \\
\hline \multicolumn{28}{|l|}{ Model } \\
\hline & 132 & 74 & & 74 & 43 & & 58 & 34 & & 97 & 51 & & 59 & 23 & & 38 & 28 & & 35 & 26 & & 15 & 20 & & 20 & 6 & \\
\hline & & & 0.021 & & & $0.41 /$ & & & 0.721 & & & $0.09 /$ & & & $0.34 /$ & & & $0.02 /$ & & & $2.08 /$ & & & $0.96 /$ & & & 0.43 \\
\hline & 105 & 57 & $0.88 /$ & 53 & 31 & 0.521 & 52 & 23 & $0.39 /$ & 63 & 36 & $0.7 /$ & 37 & 18 & $0.55 /$ & 26 & 18 & $0.87 /$ & 42 & 18 & $0.14 /$ & 16 & 13 & 0.32 & 26 & 5 & 0.50 \\
\hline AA & $(44 \%)$ & $(43 \%)$ & 0.9 & $(41 \%)$ & $(42 \%)$ & 1.0 & $(47 \%)$ & $(40 \%)$ & 0.7 & $(39 \%)$ & $(41 \%)$ & 0.5 & $(39 \%)$ & $(44 \%)$ & 1.2 & $(41 \%)$ & $(39 \%)$ & 0.9 & $(55 \%)$ & $(41 \%)$ & 0.5 & $(52 \%)$ & $(39 \%)$ & 0.5 & $(56 \%)$ & $(45 \%)$ & 0.6 \\
\hline \multicolumn{28}{|l|}{ Recessive } \\
\hline \multicolumn{28}{|l|}{ Model } \\
\hline & 34 & 18 & & 18 & 13 & & 16 & 6 & & 27 & 12 & & 16 & 6 & & 11 & 6 & & 7 & 7 & & 2 & 7 & & 5 & & \\
\hline \multirow[t]{3}{*}{ GG } & $(14 \%)$ & $(14 \%)$ & & $(14 \%)$ & $(17 \%)$ & & $(14.5 \%)$ & $(11 \%)$ & & $(17 \%)$ & $(14 \%)$ & & $(17 \%)$ & $(15 \%)$ & & $(17 \%)$ & $(13 \%)$ & & $(9 \%)$ & $(16 \%)$ & & $(6 \%)$ & $(21 \%)$ & & $(11 \%)$ & 0 & \\
\hline & & & $0.03 /$ & & & $0.41 /$ & & & $0.53 /$ & & & $0.4 /$ & & & $0.088 /$ & & & $0.35 /$ & & & $1.27 /$ & & & $2.88 /$ & & & \\
\hline & 203 & 113 & $0.86 /$ & 109 & 61 & 0.521 & 94 & 51 & $0.46 /$ & 133 & 75 & $0.52 /$ & 80 & 35 & 0.76 & 53 & 40 & $0.55 /$ & 70 & 37 & $0.25 /$ & 29 & 26 & $0.08 /$ & 41 & 11 & $1.31 /$ \\
\hline $\mathrm{AG}+\mathrm{AA}$ & $(85 \%)$ & $(86 \%)$ & 1.05 & $(85 \%)$ & $(83 \%)$ & 1.0 & $(85.4 \%)$ & $(89 \%)$ & 0.75 & $(83 \%)$ & $(86 \%)$ & 1.08 & $(83 \%)$ & $(85 \%)$ & 1.16 & $(83 \%)$ & $(87 \%)$ & 1.38 & $(90 \%)$ & $(84 \%)$ & 0.52 & $(94 \%)$ & $(79 \%)$ & 0.25 & $(89 \%)$ & $(100 \%)$ & 0.25 \\
\hline Alleles & & & & & & & & & & & & & & & & & & & & & & & & & & & \\
\hline & & & $0.001 /$ & & & $0.10 /$ & & & & & & & & & & & & & & & & & & & & & \\
\hline & 166 & 92 & $0.97 /$ & 92 & 56 & $0.74 /$ & 74 & 40 & & 124 & 63 & & & 146 & & 49 & 34 & & 42 & 33 & & 17 & 27 & & 25 & 6 & \\
\hline G & $(35 \%)$ & $(35 \%)$ & 0.99 & $(36 \%)$ & $(38 \%)$ & 0.77 & $(33.6 \%)$ & $(35 \%)$ & & $(39 \%)$ & $(36 \%)$ & & $75(39 \%)$ & $(73 \%)$ & & $(38 \%)$ & $(37 \%)$ & & $(27 \%)$ & $(38 \%)$ & & $(27 \%)$ & $(41 \%)$ & & $(27 \%)$ & $(27 \%)$ & \\
\hline & & & & & & & & & $0.07 /$ & & & $0.31 /$ & & & $0.33 /$ & & & $0.04 /$ & & & $2.73 /$ & & & 2.51 & & & o/ \\
\hline & 308 & 170 & & 162 & 92 & & 146 & 74 & $0.79 /$ & 196 & 111 & $0.57 /$ & & 53 & $0.5 /$ & 79 & 58 & $0.84 /$ & 112 & 55 & $0.09 /$ & 45 & 39 & 0.11 & 67 & 16 & 1/ \\
\hline A & $(65 \%)$ & $(65 \%)$ & & $(64 \%)$ & $(62 \%)$ & & $(66.3 \%)$ & $(65 \%)$ & 1.4 & $(61 \%)$ & $(64 \%)$ & 1.11 & $117(61 \%)$ & $(27 \%)$ & 0.23 & $(62 \%)$ & $(63 \%)$ & 1.05 & (73\%) & $(62 \%)$ & 0.62 & $(72 \%)$ & $(59 \%)$ & 0.54 & $(73 \%)$ & $20_{(73 \%)}$ & 0.99 \\
\hline
\end{tabular}


Table 2: Genotype frequencies of LEPR rs1137101 variant across different obesity grades

\begin{tabular}{|c|c|c|c|c|c|c|c|}
\hline \multirow[b]{3}{*}{ Grades of obesity } & \multicolumn{6}{|c|}{ Obesity Status } & \multirow{3}{*}{$\chi^{2 / p}$} \\
\hline & \multicolumn{2}{|c|}{ Obese } & & \multicolumn{3}{|c|}{ Non-obese } & \\
\hline & GG & GA & $\mathrm{AA}$ & GG & GA & AA & \\
\hline Grade I obese $(\mathrm{BMI} \geq 30)$ & $22 \%$ & $42 \%$ & $36 \%$ & & & & $2.07 / 0.355$ \\
\hline Grade II obese $(\mathrm{BMI} \geq 35)$ & $13 \%$ & $43 \%$ & $44 \%$ & $13 \%$ & $46 \%$ & $41 \%$ & $0.17 / 0.91$ \\
\hline Grade III obese $(\mathrm{BMI} \geq 40)$ & $15 \%$ & $32 \%$ & $53 \%$ & & & & $1.85 / 0.39$ \\
\hline
\end{tabular}


Table 3: Differences of anthropometric and metabolic traits across genotypes of LEPR variant (mean \pm SEM)

Data is presented as mean \pm SEM and was compared by ANOVA followed by Tukey post hoc test. $P<0.05$ was

\begin{tabular}{|c|c|c|c|c|}
\hline & $\mathbf{A A}$ & $\mathbf{A G}$ & GG & \\
\hline & $n=162$ & $\mathrm{n}=\mathbf{1 5 6}$ & $\mathrm{n}=54$ & $P$-value \\
\hline Body Weight (Kg) & $82.42 \pm 2.55$ & $77.41 \pm 3.47$ & $73.4 \pm 2$ & 0.262 \\
\hline Height (m) & $1.54 \pm 0.016$ & $1.59 \pm .01$ & $1.57 \pm 0.01$ & 0.217 \\
\hline $\operatorname{BMI}\left(\mathrm{Kg} / \mathrm{m}^{2}\right)$ & $33.69 \pm 0.68$ & $30 \pm 1.06$ & $29.38 \pm 2$ & 0.603 \\
\hline Waist(cm) & $102.3 \pm 1.71$ & $92.3 \pm 2.5$ & $91.19 \pm 1.77$ & 0.622 \\
\hline Hip (cm) & $111.8 \pm 1.88$ & $104 \pm 2.18$ & $102 \pm 1.77$ & 0.485 \\
\hline WHR & $0.91 \pm 0.007$ & $0.87 \pm .01$ & $0.88 \pm 0.006$ & 0.925 \\
\hline SBP(mmHg) & $121.45 \pm 1.80$ & $116 \pm 1.8$ & $115 \pm 1.4$ & 0.613 \\
\hline DBP(mmHg) & $82 \pm 1.18$ & $78 \pm 1.3$ & $77.8 \pm 0.95$ & 0.436 \\
\hline FBS(mg/dl) & $103.32 \pm 3.98$ & $93.1 \pm 2$ & $97.3 \pm 2.64$ & 0.536 \\
\hline Insulin $(\mu \mathrm{IU} / \mathrm{ml})$ & $22.50 \pm 1.93$ & $15.7 \pm 2.9$ & $16.6 \pm 1.37$ & 0.841 \\
\hline HOMA & $5.12 \pm 0.51$ & $3.5 \pm .71$ & $3.84 \pm 0.36$ & 0.887 \\
\hline Leptin(ng/ml) & $28.78 \pm 3.8$ & $22.08 \pm 1.838$ & $24.28 \pm 1.81$ & 0.504 \\
\hline Leptin receptor(ng/ml) & $15.53 \pm 0.93$ & $18.67 \pm 1.65$ & $17.3 \pm 0.79$ & 0.956 \\
\hline
\end{tabular}

considered statistically significant 


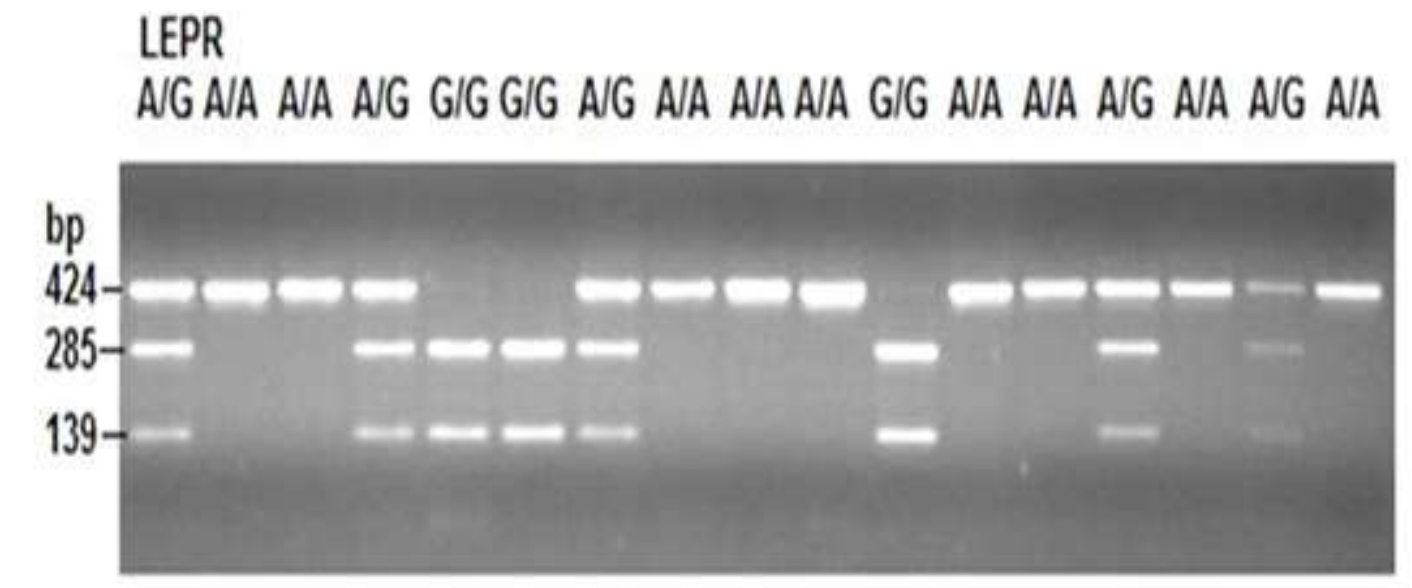

Figure. Restriction Fragment Length Polymorphism (RFLP) analysis of rs1137101 variant in the LEPR gene. 